who quotes the original Steleopyga in the synonymy under Blatta. The only species, orientalis, included under this emended form by Fischer is not ineluded by Shelford, who uses the name for a group of species typlified by the Blatta rhombifolia of Stoll. This group of speeies which Mr. Shelford lists under Stylopyga is separable from the species of the genus Blatta only by the length and development of wings in the male and can thus all be logically referred to that genus. Therefore the twenty-five species listed by Shelford in the above paper are transferred to the genus Blatta.

The genus Dorylixa of Stal is very closely allied to Blatta and will eventually very likely prove a synonym of that genus.

\title{
LUCILIA SERICATA AS A HOUSEHOLD PEST.
}

\author{
Br A. P. Monse, \\ Wellesley College, Mass.
}

In October, 1910, a lady asked me, "Why do worms prefer oriental rugs to Wilton carpets?" Inquiry revealed the fact that one of her friends was finding large numbers of white "worms" under her oriental rugs.

Naturally my first thought was of fleas and Dermestid larræ, but the description was at variance with either, neither dogs or cats were about, the rugs had been recently cleaned, and the house was immaculately kept,- -so I requested samples. In a few days a vial containing several Museid maggots and a puparium was received. Careful questioning in regard to food material for such ereatures finally secured the information that a squirrel family had been evieted recently from one of the chimneys and that one of the young squirrels, it was believed, liad died in the flue. This clue accounted satisfactorily for the presence of the troublesome maggots and the sequel. With this introduction, the following extracts from letters coneerning the outbreak will be self explanatory, due allowance being made, if thought necessary, for a possible, but under the cireumstances, very pardonable, exaggeration in regard to the numbers of the pest.

[Nov. 23] "Mrs. - writes me that you would like to hear about our 'squirrels.' On Sept. 17 squirrel No. 1 eame down the chimney and took possession of the lower part of the house, 
and on the following day No. 2 raced through the second story rooms. The chimney was then covered with netting and as there seemed to be two youngsters left in the chimney, the poor mother sat and cried on the outside of the wire. It was either the 22 nd or 23rd that one of those in the chimney was coaxed out, but the other was never heard from and probably died in the chimney although we have tried every way possible to find the body.

"On 'Thursday, Oct. 6, I noticed small white crawling things under a rug-then, lifting the corners of other rugs, found thousands. Under fifteen oriental rugs we swept up several dustpans full, but none from under the Wilton carpet rug in the livingroom, which of course made us think that they had something to do with the rugs. Our rugs we have had for several years, and they were all cleaned with vacuum cleaner about the middle of September.

"On my return from Boston, Friday, Oct. 14, the day I gave the specimens of maggot (or whatever it was) to Mrs. - I I found that the family had been killing green flies all day by hundreds. They swarmed on the windows and were swept down and killed. They died hard-had to be burned or brushed into Dalmatian powder. It was exciting! This lasted for over a week. Te gave up everything to kill flies. At first they were shiggish but later in the season they were harder to kill.

"My mother thinks that there is some connection between dead squirrel and fly-but why did they choose oriental rugs and not those of American manufacture? There were more found in the hall than in the rooms. 'The fireplaces from the squirrels' chimney are in the living-room and hall and there were more worms in those rooms. We are so anxious to know something about them-why we were so pestered, and if we have this to look forward to each October. . . I should have said that there are no birds or animals in the house and that the whole house was thoroughly cleaned just before the squirrels made their appearance-that was why we felt so disturbed."

[Jan. 4] "As to the rugs-on each floor is a large rug, and one in each doorway, leaving a space all around the rooms of about $11 / 2$ to 2 feet. All are oriental excepting the large one in the living-room. Most of the larve were found in the hall and recep- 
tion-room, and in the front of the living-room. The rugs in the bay-windows were the most popular, excepting the large one in the hall, and it was at the front windows in the living and reception rooms that the flies swarmed.

"We are still finding three or four [flies] daily."

The flies, several of which were sent me, proved on examination by Mr. C. W. Johnson to be Lucilia sericata Meigen, a common green-bottle fly.

The accompanying plan and scale will make clear the relation of chimney, rugs, and windows, and the direction and length of the larval migration. The house faces nearly west.

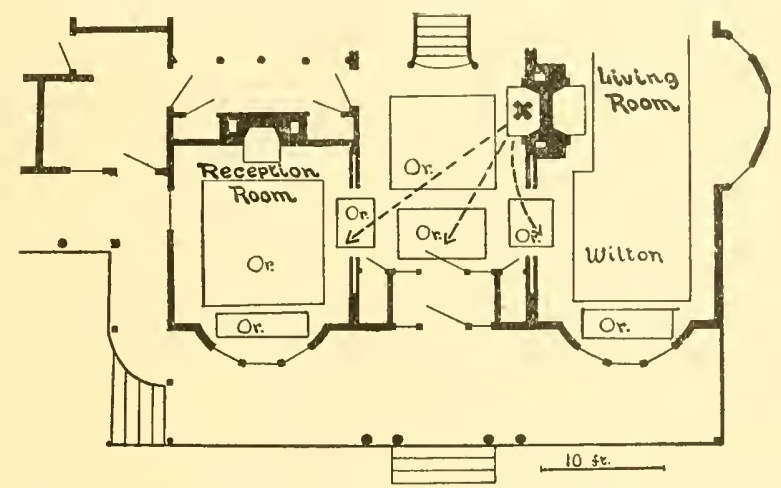

Fig. 1. $\mathbf{X}=$ fireplace of squirrel's chimney. The maggots were most numerous under the oriental rugs in the front of the hall and in the two bay windows at front of house.

Judging from the data secured, the odor of the decaying carcass of the squirrel, passing out of the top of the chimney, led to it the female flies secking suitable places to oviposit. The larva of Phormia regina, an allied species, have been observed by Folsom to be negatively phototropic until maturity, when they become positively phototropic for a brief period, seek the light, leaving the food to travel to some distance; then, becoming negatively phototropic again, they seek shelter in which to pupate. Apparently, the larve of Lucilia sericata exhibit similar tropisms. This behavior, it is easy to see, is adaptive in character, resulting in the development and preservation of larger numbers, under natural conditions, than if the larvæ remained in the food material.

Although all of the larvæ that could be found were destroyed, it is evident from the abundance of the flies that many escaped 
observation, perhaps remaining in the chimney, or being overlooked in the registers, etc.

The preference of the maggots for the oriental rugs rather than the Witton was probably due to the softer texture of the lower side of the former, and the greater rigidity and weight of the latter. Possibly additional reason may be found in the character of the dyes used, which are said to be very largely of vegetable origin in the oriental rugs. To determine if this was also a factor experimentation would be necessary.

It is needless to say that assurance was given that there was little likelihood of a repetition of the disagreeable occurrence.

\section{THE POMONA JOURNAL OF ENTOMOLOGY.}

Publisied bY tile Biological Department of Pomona College.

The only entomological journal published on the Pacific slope. A well established, high class quarterly in its second year, fully illustrated, and devoted to original investigations in economic, biologic and taxonomic entomology. Indispensible to working entomologists everywhere. Price merely nominal- $\$ 1.00$ to domestic and $\$ 1.25$ to foreign postal countries. Separates of any articles always available. Address,

Pomond Journal of Extomology, Claremont, California.

\section{ENTOMOLOGICAL NEWS}

A forty-eight page illustrated magazine, published monthly except in August and September, devoted to the study of INSECT LIFE. It contains a resumé of the proceedings of a number of Entomological Societies, and also articles by the leading Entomologists in the United States and Canada. Valuable information for the beginner, the economic entomologist and the systematist. TWO DOLLARS a year in advance. Single copies 25 cents. Address

\section{ENTOMOLOGICAL NEWS}

The Academy of Natural Sciences

1900 RACE STREET.

PHILADELPHIA, PA. 

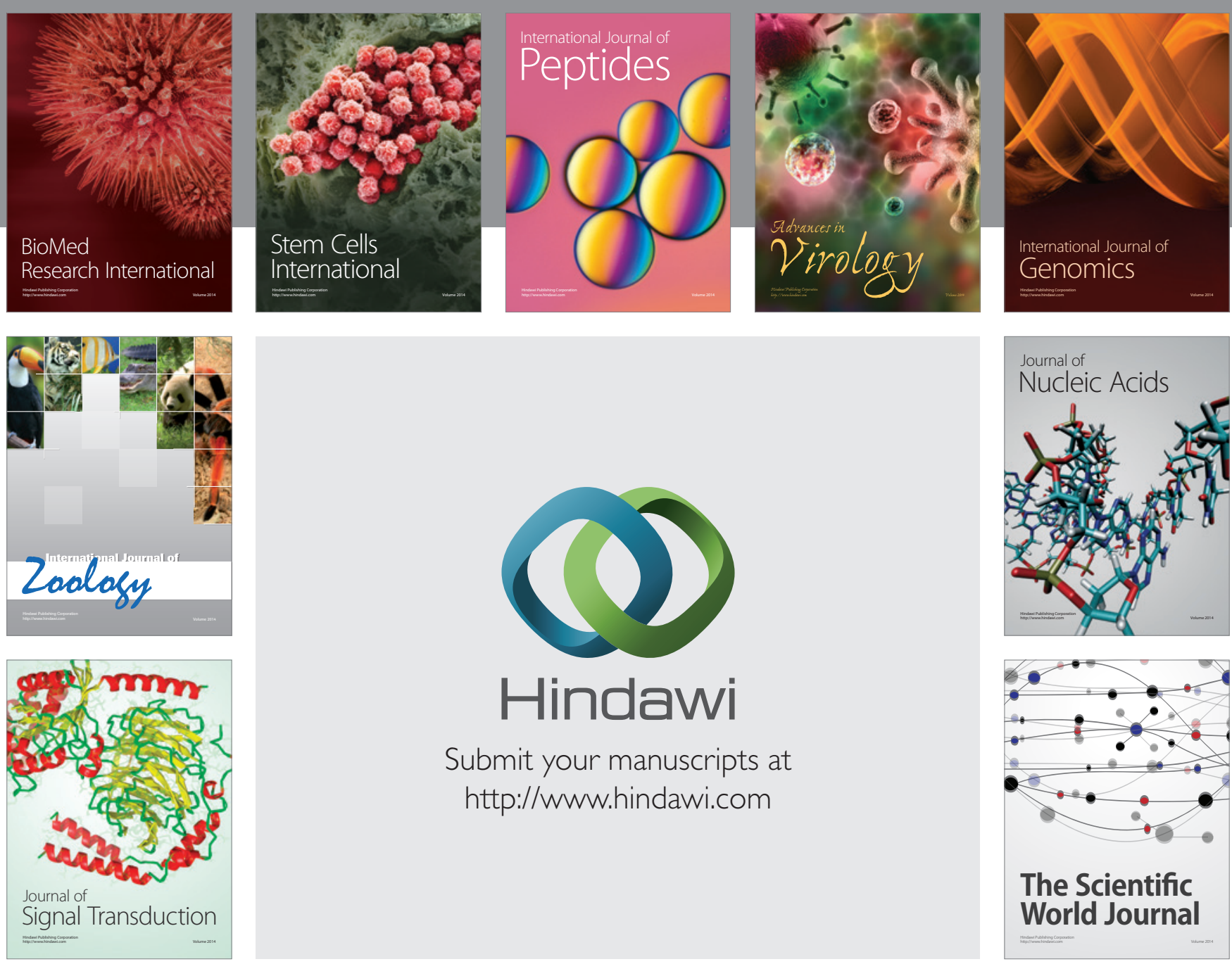

Submit your manuscripts at

http://www.hindawi.com
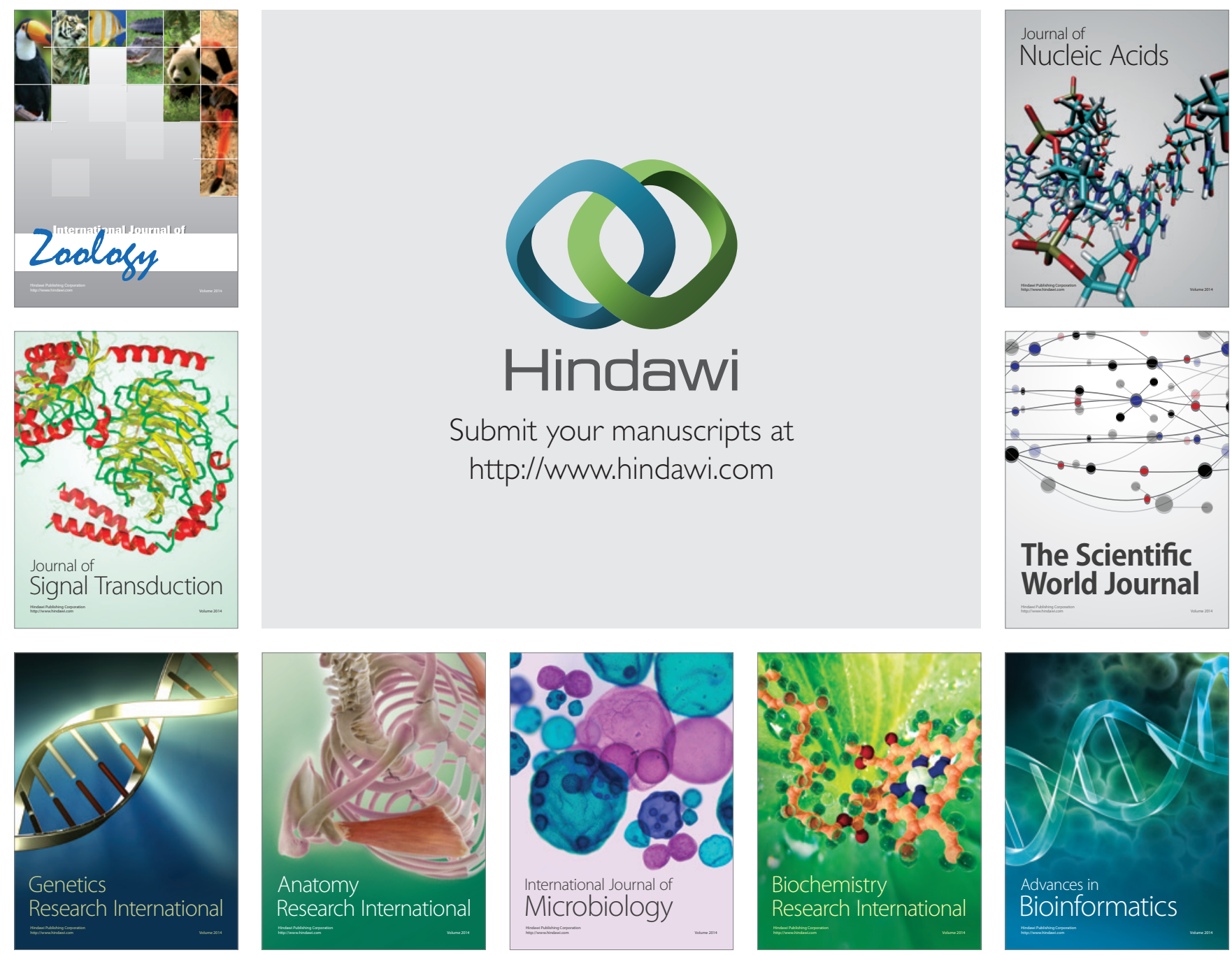

The Scientific World Journal
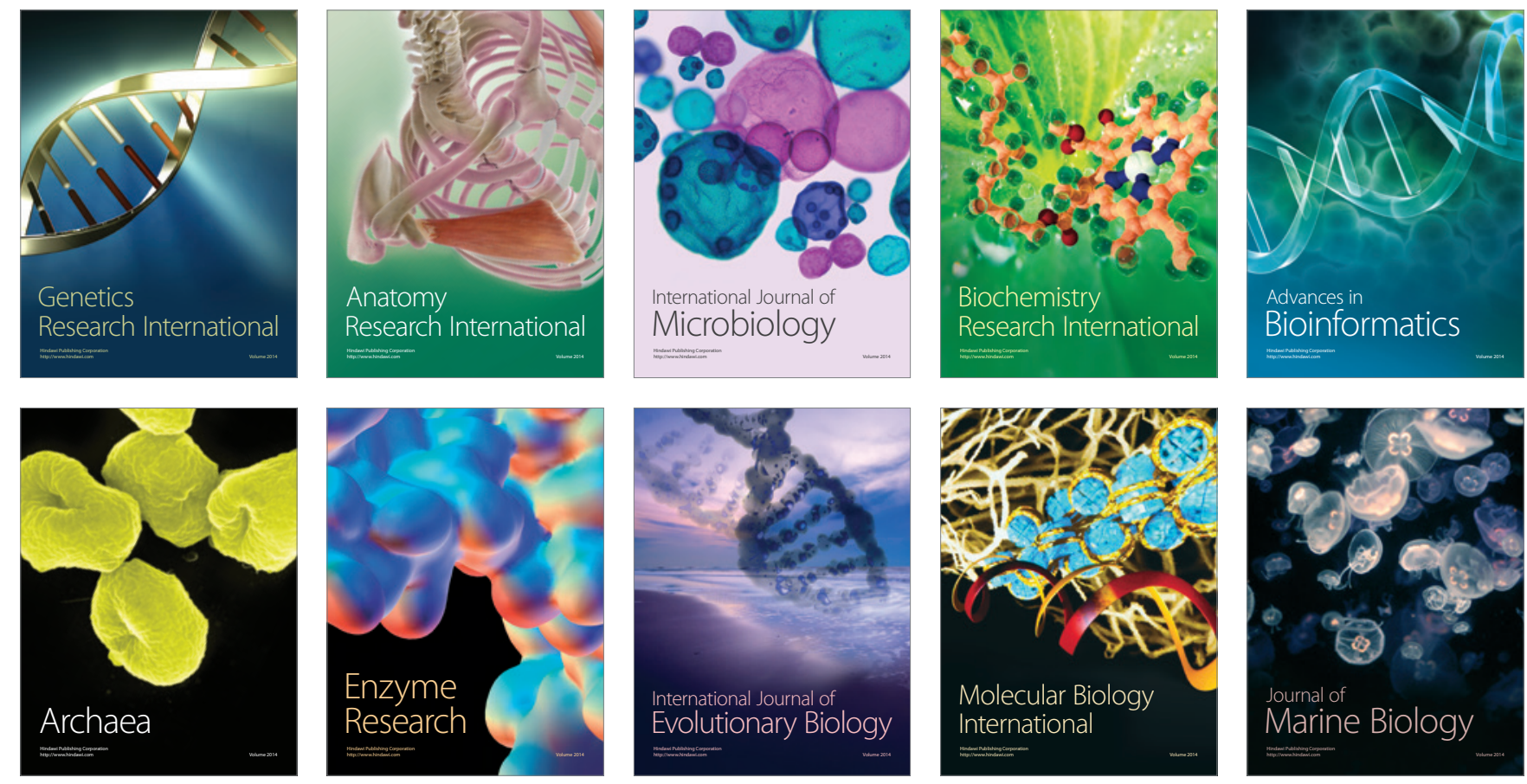